\title{
- Trabalho como Representação: a visão dos jovens universitários
}

\author{
Sidinei Rocha de Oliveira ${ }^{1}$ \\ Valmiria Carolina Piccinini ${ }^{2}$ \\ Cássia da Silva Silveira ${ }^{3}$
}

\section{Resumo}

Um dos momentos de expressiva mudança na relação do indivíduo com o mundo do trabalho está na transição da juventude para a vida adulta, quando, entre outras modificações (biológicas, psicológicas e sociais), o ingresso no mercado de trabalho tem papel fundamental como marco de uma nova etapa de vida. Assim, este estudo busca analisar quais representações sociais que estão presentes nas falas de jovens estudantes de um curso de Administração no que se refere à sua compreensão do que seja "trabalho". Para tanto, foram consultados 120 jovens universitários, dos primeiros semestres do curso noturno de Administração de uma universidade do Sul do Brasil. As respostas sobre "o que é trabalho" e "o que não é trabalho" foram escritas pelos próprios informantes e analisadas posteriormente, considerando tanto a representatividade com que as respostas ocorreram quanto sua diversidade. De modo geral, nota-se que o trabalho continua a ser compreendido como atividade central que estrutura a vida dos indivíduos e da sociedade em geral, é uma forma de integração social, prevalecendo sua imagem como um elemento que insere o individuo ao meio, capaz de promover sua realização pessoal, profissional e a do sustento financeiro.

Palavras-chave: Trabalho. Representações Sociais. Jovens Universitários. Administração.

\footnotetext{
${ }^{1}$ Doutor em Administração pela Universidade Federal do Rio Grande do Sul (PPGA/EA/UFRGS) e pela Université Pierre-Mendès-France (UPMF). Professor Adjunto da Faculdade de Administração, Ciências Contábeis e Turismo/Universidade Federal Fluminense. Endereço: Rua São Paulo, 30 -Centro-Niterói -RJ-Brasil. CEP: 24020-150. E-mail: sidroliveira@hotmail.com.

${ }^{2}$ Doutora em Economia do Trabalho e da Produção pela Université Pierre-Mendès-France (UPMF). Professora Associada do Programa de PósGraduação em Administração/Escola de administração/Universidade Federal do Rio Grande do Sul (PPGA/EA/UFRGS) Endereço: Rua Washington Luís, 855, sala 422 Centro - Porto Alegre - RS - Brasil. CEP: 90010-460. E-mail: vpiccinini@ea.ufrgs.br.

${ }^{3}$ Bacharel em Administração da Escola de Administração da Universidade Federal do Rio Grande do Sul Endereço: Rua Washington Luís, 855 , sala 422 - Centro - Porto Alegre - RS - Brasil. CEP: 90010-460. E-mail: cassiasilveira@yahoo.com.br.

Artigo recebido em: 16/06/2010. Aceito em: 26/10/2010. Membro do Corpo Editorial Científico responsável pelo processo editorial: João Nilo Linhares.
} 


\section{Introdução}

Ao longo da vida, as pessoas têm o trabalho sob diferentes concepções, de acordo com o seu histórico profissional (mesmo que seja uma prénoção antes do ingresso), com o contexto social em que se encontram e seus grupos de referência de cada período. Um dos momentos mais expressivos de mudança na relação do indivíduo com o mundo do trabalho está na transição da juventude para a vida adulta, quando, entre outras modificações (biológicas, psicológicas e sociais) e ritos de passagem, o ingresso no mercado de trabalho desponta como importante marco simbólico.

Além disso, as atuais transformações nas relações laborais têm atingido diretamente os jovens que, ao ingressarem no mercado de trabalho, se deparam com uma realidade para a qual não foram preparados. Os gestores de grandes organizações, ao mesmo tempo em que apontam a importância da valorização do capital intelectual e a de reconhecer a relevância das pessoas e seu desenvolvimento como fontes primordiais de vantagens competitivas sustentáveis, buscam a contínua automatização e rotinização de funções e, por consequência, promovem o aumento dos vínculos flexíveis, precários e informais.

Como resultado, verifica-se que apesar dos jovens entre 15 e 24 anos corresponderem a $20 \%$ da população economicamente ativa (segundo dados do Ministério do Trabalho e Emprego), eles constituem 44\% dos desempregados (CHAHAD; PICCHETTI, 2003). O crescimento do desemprego e a carência de boas oportunidades de trabalho levam diariamente jovens profissionais a buscarem ingresso no mercado de trabalho, que apresenta cada vez maiores exigências de qualificação, mesmo para as vagas dos níveis mais elementares (MELO; QUIROGA, 2003).

Para aprofundar a compreensão sobre a relação entre trabalho e juventude, este estudo busca analisar quais representações sociais estão presentes nas falas de jovens estudantes do curso de Administração no que se refere à sua compreensão do que seja "trabalho". Considerando o momento de passagem que esses indivíduos se encontram $e$ as mudanças que têm ocorrido no mercado de trabalho (maior flexibilização das relações de trabalho, crescimento do terceiro setor, elevação do desemprego juvenil, heterogeneização da classe trabalhadora, entre outros), e que esse é o grupo no qual potencialmente se encontram os futuros gestores das organizações nacionais, cabe questionar: Que representações os jovens do ensino superior têm sobre o 
trabalho? Essa nova configuração do mercado de trabalho traz novas significações para a compreensão desses sujeitos sobre a prática laboral?

Para atender essas questões, foram consultados 120 jovens universitários dos primeiros semestres do curso noturno de Administração. As respostas sobre "o que é trabalho?" e "o que não é trabalho?" foram escritas pelos próprios informantes e analisadas posteriormente, considerando-se tanto a representatividade com que ocorreram quanto sua diversidade. A partir desses dados são realizadas algumas inferências, destacando elementos sociais que contribuíram para firmar tais representações, bem como reforços a crenças presentes no atual contexto vivido pelos participantes.

A teoria das representações sociais, na vertente da psicologia social francesa, baseia-se na relação entre o indivíduo e o meio social em que está inserido, revelando a subjetividade como algo que emerge da relação entre o individual e o coletivo (CAVEDON, 1999). As representações sociais mostram como o imaginário particular do indivíduo está ligado às significações coletivas da sociedade da qual participa.

Compreender as representações sobre o trabalho presentes no pensamento dos jovens contemporâneos nos oferece uma possibilidade de compreensão de "como" as alterações do mundo do trabalho os têm influenciado e, na medida em que muitos deles ainda não ingressaram no mercado, grande parte das ideias que emergirem aponta os efeitos dos processos de socialização na família e na escola, bem como as informações recebidas pela mídia impressa e televisiva, sem necessariamente estarem vinculadas com a materialidade da vida no trabalho.

\section{Um Mundo como Representação}

Entre os precursores dos estudos em representações sociais está Durkheim que desenvolve as primeiras ideias ao estudar o conceito de representações coletivas, as quais apresentam uma mudança de compreensão ao longo de sua obra. Desde "Da Divisão do Trabalho Social" (1883) até as "Formas Elementares da Vida Religiosa" (1912), verifica-se que a ênfase se desloca da morfologia social, cujo mecanismo é o principal fundamento explicativo na primeira obra, para a valorização do simbolismo coletivo como princípio pelo qual se funda a realidade social, expressos nesta última. As representações coletivas - como síntese dos elementos dispersos no meio 
social - remetem à natureza que está acima do homem como ser individual, exprimem o ideal coletivo que tem origem na religião (DURKHEIM, 1996). São representações impessoais e estáveis, comuns a todos, na medida em que se constituem a partir dos indivíduos como grupo, e configuram-se como instrumentos de compreensão do mundo e comunicação com as razões individuais.

Partindo da noção de representação coletiva de Durkheim (1996), Moscovici (1997) desenvolve a vertente europeia da psicologia social, considerando que o conceito durkheimiano apresenta uma categoria coletiva que deve ser compreendida no nível da relação entre o individuo e a sociedade. Contudo, estabelece o termo representações sociais, pois considera mais adequado para a compreensão da diversidade e da velocidade em que as transformações econômicas, políticas e culturais ocorrem na sociedade moderna. Como disciplina, a psicologia social estuda como se dá a relação entre sociedade e indivíduo, visto que cada pessoa é

[...] tanto um agente de mudança da sociedade como é um produto de mudança desta sociedade, assim a teoria das representações sociais cobre de forma mais adequada o quanto o indivíduo é um produto da sociedade (FARR, 1997, p. 51).

Deve ser destacado que esse braço da psicologia social difere significativamente de sua vertente americana, que, com antecedentes em August Comte, tem uma visão mais focada no indivíduo. Assim, a psicologia social europeia constitui uma forma sociológica de compreender a relação entre sujeitos e grupos, apresentando uma separação entre individualismo e coletivismo menos pronunciada. Já a americana baseia-se em uma visão mais psicológica, reafirmando que nos países em que predomina a tradição protestante e de conflito reflete uma visão mais individualista, o que explicaria a tradição dos estudos de representações sociais ser mais forte na Europa Meridional (FARR, 1997).

Para Jodelet (1993), na psicologia social, as representações sociais relacionam as diferenças entre os processos mentais individuais estudados pela psicologia cognitiva e os outros sistemas de ideias e conhecimentos socialmente produzidos como a ciência, a ideologia, os mitos, etc. Desse modo, as representações sociais podem ser compreendidas como uma forma de conhecimento corrente, chamado de senso comum, tendo as seguintes características: a) são socialmente elaboradas e partilhadas por se constituírem a 
partir de experiências individuais, mas também pelas informações, saberes, modos de pensar que recebemos e transmitimos pela tradição, pela educação e pela comunicação social; b) é uma visão prática de organização, de domínio, de desenvolvimento (material e social) e de orientação das condutas e comunicações; c) contribui para o estabelecimento de uma visão de realidade comum ao todo social (grupo, classe, etc.) ou cultural.

Convém destacar o que diz Cavedon (2005, p. 11):

A representação social vincula-se à ordem do simbólico, de modo que determinadas coisas (materiais e imateriais) vão ter significados diferentes dependendo da cultura do grupo social na qual ganham significações. A diversidade traz a dificuldade de se conhecer e reconhecer saberes circulantes, acarretando, de certo modo, entraves na comunicação, em razão de não dominar as significações que determinados grupos atribuem às coisas que compõem seus universos simbólicos e com os quais muitas vezes interagem.

As representações podem ser identificadas e analisadas por meio "das convenções dentro das quais se elaboram os saberes populares e o senso comum" (MOSCOVICI, 1997, p. 9), conferindo racionalidade a essa crença coletiva. Contudo, não se pode considerar que apenas esses saberes populares - o dito senso comum - expressem as representações sociais, pois elas também estão contidas nas ciências, religiões, ideologias, etc. e, portanto, devem ser consideradas também como inculcadas de representações.

$\mathrm{Na}$ teoria das representações sociais desenvolvida por Moscovici (1997) destaca-se que a dicotomia individual-coletivo não permite que se compreendam todas as faces do que acontece com os seres humanos que são ao mesmo tempo individuais e sociais (CAVEDON, 2005). O conflito entre o individual e o coletivo não é somente do domínio da experiência de cada um, mas é igualmente realidade fundamental da vida social. Além do mais, todas as culturas possuem instituições e normas formais que conduzem, de uma parte, à individualização, e de outra, à socialização (MOSCOVICI, 1997, p. 12). Esse cruzamento entre o indivíduo e o social confere originalidade na forma como se trabalha a relação entre eles, bem como permite compreender interesses relacionados nas ideologias, construções cientificas que se reforçam sobre os conhecimentos do senso comum (JODELET, 1993). 
As construções e significados transmitidos descrevem, explicam e prescrevem o fazer: fornecem uma forma canônica de compreender de uma determinada época, de se apresentar e de se conduzir em sociedade, e mesmo em espaços pessoais; avaliar os outros e se situar em relação a eles. Da mesma forma, é uma representação interna, uma forma na qual os sujeitos intervêm no mundo ao qual pertencem. Essa intervenção dá às representações sociais sua especificidade para relacionamento com as outras produções mentais sociais: ideologia ou ciência. A construção mental operada faz parte de propriedades cognitivas que o sujeito dispõe para tratar com os demais, da dinâmica psicológica de seu projeto de significações, bem como da bagagem cultural que o sujeito obteve em suas melhores relações com os outros. Os processos de elaboração cognitiva podem ser ditos sociais, em um primeiro sentido, quando eles se produzem na interação e comunicação com os outros. Eles estão ligados a uma atividade conjunta de participantes que constroem certa interpretação ou visão partilhada de um objeto de interesse do senso comum (JODELET, 1993).

Quando transferidas de um meio social para outro, as representações sociais reorganizam-se, podendo ganhar novos significados, algumas vezes diferentes daqueles que possuíam em seu local de origem. Nesse sentido, as práticas sociais levam a "reelaborações simbólicas" com objetivo de desenvolver também novas ações, que levarão a formas diferentes de representação. Essa interação e contínua reconfiguração das representações possibilita, tanto a estabilidade e o reforço de identidades, também, confrontá-las a partir dos significados compartilhados, revelando o dinamismo do meio social (CAVEDON, 2005).

No que se refere ao trabalho, em diferentes culturas e momentos históricos, existiram (e existem) variadas representações e concepções, de acordo com as funções que ele tinha no corpo social e aqueles que o desempenhavam. Na seção seguinte, apresenta-se um breve apanhado das principais representações e mudanças de compreensão sobre o trabalho ao longo do tempo.

\subsection{O Trabalho como Representação}

Nas sociedades antigas (grega e romana), o trabalho estava ligado apenas à sobrevivência. No caso dos gregos, tudo aquilo que estava ligado às necessidades não era capaz de definir a liberdade nem a grandeza do homem. Essa concepção clássica de trabalho não valorizava nem a tarefa nem 
o indivíduo (ENRIQUEZ, 1999). Além disso, o trabalho é visto como algo que tortura, algo degradante e inferior. Essa ideia sobre o trabalho teria se espalhado por todos os países latinos que se formavam e perdurou em parte deles até o início do Século XV (ALBORNOZ, 1994).

$\mathrm{Na}$ Idade Média (Séculos $\mathrm{V}$ até $\mathrm{XV}$ ), com o crescimento das religiões cristãs, é possível identificar o surgimento de valores positivos no conceito de trabalho. Esse conceito passa a ser percebido como um esforço físico ou intelectual direcionado para algum fim. "O significado ativo e desejado para realização de objetivos; onde até mesmo o objetivo realizado passa a ser chamado trabalho. Trabalho é o esforço e também seu resultado" (ALBORNOZ, 1994, p. 12). O trabalho torna-se uma das categorias capazes de distinguir o ser humano dos animais, pois o homem, além de ser capaz de realizá-lo, teria a possibilidade de interrompê-lo no momento em que decidisse, mesmo que contrariasse suas necessidades, pois o "trabalhar" não estaria vinculado aos seus instintos, mas à sua liberdade de ação. Entretanto, é condenada a atividade que tem por objetivo principal o lucro.

A Reforma Protestante (Século XVI) levou à alteração de valores e comportamentos, ao passar a dar destaque para a vida ativa, desenvolvida em uma profissão. $\mathrm{O}$ trabalho passou a ser mais valorizado, sendo compreendido como meio que permite a obtenção de riquezas, que resulta em uma busca intensa pela produtividade. Além disso, com o crescimento da economia mercantil, o trabalho passou a ser ressaltado, tendo grande valor para o processo econômico. Os indivíduos que não trabalhavam eram vistos como parasitas, delinquentes ou inúteis (ENRIQUEZ, 1999).

O crescimento do capital financeiro introduz uma nova dinâmica na economia, indicando um uso mais estrito do tempo para produzir a valorização do capital e prestigiando os empresários empreendedores e exitosos. O objetivo das empresas que surgem consiste em dominar a natureza para extrair os recursos e manufaturá-los, tendo em vista a obtenção de benefícios, com a utilização da técnica (NEFFA, 2003).

A Primeira Revolução Industrial (1760-1850) marca a transição do capitalismo mercantil para o capitalismo industrial. Nesse período, os economistas clássicos (Adam Smith, David Ricardo e John Stuart Mill) produzem estudos que apontam mudanças relevantes com respeito à importância relativa do dinheiro, dos setores produtivos e dos fatores de produção. Na era industrial, continua crescente a valorização do trabalho, que se torna um símbolo de liberdade do homem, para transformar a natureza e a sociedade. 
Essa revolução no pensamento liberta os indivíduos dos antigos laços com a terra, pois cada um transforma-se em um trabalhador livre, que oferece sua força e seu intelecto a quem lhe remunerar por sua atividade.

No período em que a Revolução Industrial encaminha-se para sua segunda fase (1850-1900), Karl Marx (1818-1883) desenvolve sua obra, na qual destaca o caráter dicotômico que o trabalho adquire na sociedade moderna. Por um lado, é considerado o elo que une o homem à natureza, integra a sociedade e realiza os indivíduos, o trabalho deve ser formador da própria condição humana, expressivo, fornecedor de recompensas de acordo com as necessidades de cada um: deve ter conteúdo, ser criativo e desafiante, de controle coletivo e protegido pelo Estado. Por outro lado, sob a égide da mercadoria, transforma-se em uma atividade imposta, forçada e compulsória (MARX, 1989; 1998).

Na virada do Século XIX, com o surgimento da grande empresa capitalista, da sociedade por ações e do grande capital financeiro, a atividade laboral realizada pelos operários constitui-se em um elemento essencial para a manutenção do sistema produtivo. Para os operários, o trabalho torna-se um elemento constitutivo e básico de sua personalidade. Para a sociedade, torna-se um elemento fundamentalmente integrador, permitindo a uma sociedade fragilizar ou reforçar laços sociais (ENRIQUEZ, 1999).

Com a influência da corrente keynesiano/fordista na economia, dos estudos da Escola das Relações Humanas e dos trabalhos iniciais sobre psicologia organizacional, forma-se uma nova concepção de trabalho que é entendida como mercadoria em um estreito vínculo com o consumo. Por um lado, o trabalho é visto como um provedor de salários, benefícios e assistência; ampla rede de proteção institucional que inclui garantia de estabilidade no emprego; provedor de contatos interpessoais; por outro lado, pobre de conteúdo, parcelado, monótono, mecanizado e repetitivo para a maior parte dos trabalhadores.

Atualmente, com as transformações que afetam o trabalho - a globalização das economias com a crescente valorização do capital financeiro, a difusão das tecnologias de informação e comunicação, a nova divisão internacional de trabalho, a preponderância da política econômica neoliberal, a reestruturação das empresas na lógica da racionalização flexível, bem como o desequilíbrio de forças no mercado de trabalho e das relações de laborais - emergem visões distintas sobre ele.

Os debates a respeito do destino do trabalho têm levado a vislumbrar uma nova sociedade cujo labor não tem mais lugar central, deixando de ser 
a referência na qual o homem se organiza em sociedade e constrói sua identidade como indivíduo. Alguns autores americanos e europeus defendem a tese do "fim do trabalho" (OFFE, 1989; RIFKIN, 1995; DE MASI, 1999; 2000; MEDA, 1999) visto que as pessoas estariam encontrando cada vez menos empregos permanentes, exercendo menos horas de atividade e ocupando o tempo livre com outras atividades fora da esfera do trabalho (lazer, família, política, religião, etc.).

Para Antunes (1999) e Cattani (2000) o trabalho continua central, visto que continua a ser fundamental na vida dos indivíduos, tanto sob o ponto de vista econômico quanto social, embora tenha adquirido novas "roupagens" como conseqüência das transformações ocorridas. Também a generalização da palavra trabalho, quando utilizada para designar diversas formas de manifestação, como a do emprego ou a de simples atividades (posto, tarefa), contribui para sua desvalorização. Contudo, o trabalho continua sendo categoria fundamental na vida dos indivíduos, na medida em que, além da dimensão econômica indispensável para a satisfação de necessidades materiais, permanece como elemento de integração. Ao funcionar como uma forma de regulação social, organiza o tempo e o espaço das atividades da vida dos indivíduos, tornando-se um elemento fundamental na constituição da condição humana, ao ser um fator determinante da experiência do indivíduo na integração social e realização pessoal, bem como um legitimador das diferentes fases da vida (estudo, atividade laboral, aposentadoria).

No Brasil, estudos recentes sobre os sentidos do trabalho (PICCININI et al., 2004; MORIN; TONELLI; PLIOPAS, 2003) confirmam sua importância na vida dos indivíduos. Nessas pesquisas, o trabalho é entendido de três dimensões: individual, capaz de proporcionar realização profissional e satisfação pessoal, além de ser um meio de subsistência; organizacional, responsável pela sentimento de pertença e reconhecimento pelos objetivos alcançados; e social, como sentimento de contribuição para o todo da sociedade e vivência ética e cidadã.

Pelo exposto, nota-se que o trabalho adquire múltiplos significados ao longo do tempo, quando tais significados foram positivos, como meio de realização pessoal e formação de identidades; quando negativos, como algo pesado e degradante ou explorador e contribuindo para a desigualdade dos indivíduos. Considerando que estamos em um período de expressivas transformações no universo de trabalho, acredita-se que ele pode estar adquirindo novos significados ou reforçando antigas representações. Para trazer no- 
vos subsídios a esta discussão, nas próximas seções busca-se mostrar como o trabalho tem se apresentado no imaginário de jovens universitários.

\section{A Condução dos Estudos em Representações Sociais}

A formação das representações sociais com elementos de conhecimento cotidiano ocorre na interação dos conteúdos que circulam na sociedade, no processo de interação social e nas pressões para definir uma dada situação de forma a confirmar e manter identidades coletivas. O contexto, neste sentido, é essencialmente "intertextual", é a justaposição de dois elementos: o texto sócio-histórico - que remete às construções sociais que alimentam nossa subjetividade - $e$ o texto - presente no discurso constituinte das relações sociais (SPINK, 1997, p. 122). Esse texto é marcado por três tempos: o tempo curto da interação que tem por foco a funcionalidade das representações; o tempo vivido que abarca o processo de socialização e as disposições adquiridas pela participação em determinados grupos sociais; e o tempo longo, domínio das memórias coletivas em que estão depositados os conteúdos culturais cumulativos do conjunto social (SPINK, 1997).

Para o estudo de representações sociais, Spink (1997) destaca que podem ser utilizados entrevistas estruturadas ou questionários dependendo do objetivo a que se propõe. Para estudo das representações sociais como processo, a autora sugere que a de coleta de dados junto aos indivíduos observados seja realizada com o auxílio de longas entrevistas semiestruturadas, ao lado da análise do contexto social ao qual o indivíduo está inserido, buscando desenvolver como as representações foram construídas. Esse processo, por ser centrado na totalidade do discurso, torna-se demorado e envolve os chamados "sujeitos genéricos", termo que designa um pequeno número de sujeitos a serem analisados. Esses sujeitos, quando bem contextualizados, têm o poder de representar a totalidade do grupo.

Já os estudos que buscam entender as representações na perspectiva dos grupos, na tentativa de encontrar tanto a diversidade quanto o que há de comum e compartilhado, têm utilizado formas de coleta de dados mais estruturadas, especialmente questionários com perguntas abertas. A estrutura da representação social é, neste caso, fruto da somatória da análise de ideias de várias respostas (SPINK, 1997). 
O presente estudo privilegiou o segundo formato de levantamento de informações, com 120 alunos de até 24 anos situados entre os dois primeiros semestres de Administração da Universidade Federal do Rio Grande do Sul, e a escolha de 24 anos como idade máxima seguiu o critério de classificação dos indivíduos jovens da ONU e, principalmente, por estarem no momento de transição entre a escola e o trabalho (parte deles ainda não trabalhava e os demais estavam nos primeiros anos de profissão). Dessa forma, acreditase que as representações construídas por esses sujeitos estejam mais pautadas pela socialização na família e na escola/universidade e em outras vivências sociais do que pela própria vivência profissional.

Os questionários constituíram-se de duas questões abrangentes em que os estudantes, após preencherem alguns dados de perfil (idade, gênero, se exerciam alguma atividade e o tempo de trabalho), dissertavam sobre o que é trabalho e o que não é trabalho, segundo a concepção de cada um. Em um segundo momento, grupos de cinco a seis buscavam elencar elementos (histórias, fábulas, ditos populares, etc.) que contribuíam para reforçar as ideias apontadas em suas respostas.

Quanto ao perfil dos participantes, $72 \%$ eram do gênero masculino, $54 \%$ exerciam alguma atividade, ainda que há pouco tempo ${ }^{4}$. Com relação à idade: $15 \%$ tinham 17 ou 18 anos, 42,5\% possuíam 19 ou 20 anos, 17\% estavam na idade entre 21 ou 22 anos e 17,5\% tinham 23 ou 24 anos.

Para análise, em um primeiro momento foi lido o conjunto das respostas para se ter uma ideia geral acerca das referências encontradas; em uma segunda leitura foram agrupados elementos que apresentavam maior frequência nos discursos dos participantes, sem deixar de observar a diversidade das respostas. Sobre esses grupos, algumas inferências são realizadas na quarta seção. As respostas dos informantes foram transcritas tal como se apresentavam, de modo que podem apresentar erros de grafia ou concordância.

Deve ser salientado que toda prática científica é uma manifestação reflexiva e crítica na qual o autor se faz presente, sendo histórica e contextualmente situada (SPINK, 2004). Assim, as inferências apresentadas na análise compõem parte das próprias representações dos autores, que, neste caso, estavam fortemente influenciadas pela vivência profissional, experiência docente e debates constantes com universitários em busca de inserção no mercado de trabalho.

${ }^{4}$ Embora não seja possível precisar o número, visto que não era foco do questionário distribuído, um número representativo de respondentes iniciava sua experiência profissional com a realização de estágios não obrigatórios. 
As representações sociais são construções sócio-históricas, sendo fundamental a apresentação do contexto em que foram estabelecidas. Assim, na próxima seção é caracterizado o espaço onde ocorre a construção dos discursos dos informantes deste trabalho, o que contribui para sua formação como grupo e nas representações que elaboram.

\section{Do Contexto aos Atores}

A história da Universidade Federal do Rio Grande do Sul - UFRGS, que marca o início da educação superior no Rio Grande do Sul, começa com a fundação da Escola de Farmácia e Química, em 1895 e, em seguida, da Escola de Engenharia. Em dezembro de 1950, a Universidade foi federalizada, passando à esfera administrativa da União. Desde então, a UFRGS passou a ocupar posição de destaque no cenário nacional como um dos maiores orçamentos do Estado do Rio Grande do Sul, ficando em primeiro lugar em publicações e em segundo em produção científica, entre as federais, considerando o número de professores que a integram ( $<$ http://www.ufrgs.br/ufrgs/ a_ufrgs/index.asp $>$ ).

As atividades da Escola de Administração da UFRGS iniciam-se junto com a Faculdade de Ciências Econômicas (FCE), com a criação, em 1951, do Instituto de Administração. Até 1996 seguia como departamento da FCE, quando o conselho Universitário da UFRGS aprovou, por meio da Decisão n. 58/96, a criação da Escola de Administração (EA) da UFRGS, tornando-a unidade autônoma (<http://www.ea.ufrgs.br/sobreaescola/historico.asp >).

Atualmente, a EA possui mais de 2.000 alunos, distribuídos nos cursos de graduação, especialização, mestrado (acadêmico, interinstitucional $e$ profissionalizante) e doutorado. Segue como uma das referências nacionais, tanto pela qualidade do ensino prestado no curso de bacharelado quanto pelo número de publicações e projetos desenvolvidos na pós-graduação.

De acordo com a publicação "PERFIS - Perfil dos Estudantes de Graduação", da Pró-Reitoria de Ensino da UFRGS (2002), é possível destacar algumas características pertinentes à análise referentes ao curso de Administração de Empresas: 62,1\% dos alunos são naturais de Porto Alegre e 60\% dos graduandos concluíram o ensino médio em instituições particulares. Quanto ao turno em que realizaram o ensino médio, $69,5 \%$ o realizam no turno da manhã, preferência essa que não ocorre no do ensino superior, já 
que mais de $60 \%$ dos entrevistados estavam matriculados no curso noturno e com quase $90 \%$ dos estudantes exercendo atividades remuneradas. Com relação às horas trabalhadas diariamente, o valor percentual significativo de $53 \%$ apontou para 8 a 9 horas diárias, seguido de $20 \%$ para 5 a 7 horas diárias trabalhadas. $\mathrm{O}$ índice sobre a principal fonte de sustento predomina na família, com $46,1 \%$, seguido de $27,9 \%$ dos alunos com renda própria.

Embora se refira ao perfil geral do curso, em que pesa a participação de alunos com mais de 25 anos, merece destaque informar que se trata de um grupo de classe social privilegiada (estudantes vindos de escolas privadas, que ainda moram com os pais), ou seja, um grupo social que representa apenas uma das juventudes (e um grupo minoritário) do conjunto do país. Também é possível verificar a tendência em ingressarem cada vez mais jovens no mercado de trabalho, transferindo seus estudos para o turno da noite e atuando em jornada de trabalho integral. Diante do exposto, busca-se na próxima seção analisar as representações sociais elaboradas por eles acerca do trabalho.

\section{As Representações sobre o Trabalho}

"Trabalho é uma atividade geralmente remunerada que estabelece uma relação de compromisso com alguma pessoa. Trabalho é necessário tanto para socialização quanto para sobrevivência" (sexo masculino, 18 anos, não trabalha).

"Trabalho é a realização de uma certa atividade com um objetivo que representa, mesmo que inconscientemente, uma forma do indivíduo se sentir parte da sociedade da qual vive. Trabalho é interação" (sexo feminino, 19 anos, não trabalha).

Como nas transcrições anteriores, a maior parte das respostas traz em seu conjunto a presença de mais de uma representação, algo que já era esperado, considerando a complexidade para compreensão do trabalho e os múltiplos fatores que contribuem para a formação das ideias de cada indivíduo. Assim, a título de uma melhor organização, as representações foram 
separadas para, posteriormente, analisar-se o contexto histórico geral que contribuiu para a formação daquela ideia sobre o termo em estudo e também se faz inferências sobre possíveis elementos presentes no processo de socialização dos informantes e crenças do imaginário do grupo ao qual pertencem.

A partir das respostas encontradas, as representações apresentadas pelos estudantes sobre trabalho podem ser classificadas como: materiais (relacionadas ao retorno monetário e aos resultados objetivos do trabalho), sociais (as que destacam a relação de sua atividade para o todo da sociedade) e subjetivo-pessoais (que representam a vinculação que fazem do trabalho na esfera individual, sem estarem relacionados diretamente com sua materialidade).

A relação do trabalho com a sua materialidade, tanto no aspecto de retorno financeiro quanto dos resultados atingidos, foi a representação mais frequente. $\mathrm{O}$ trabalho como meio de troca por moeda é expresso tanto na forma positiva quanto negativa. Se, por um lado, eles destacam que a atividade laboral é fonte de sustento, de suprir necessidades básicas, de permitir alcançar os bens e os planos almejados, um meio de garantir a liberdade de escolha e permitir "construir" algo, por outro, eles evidenciam a não obrigatoriedade de que isso tenha uma compensação como troca, conforme se observa a seguir.

"Trabalho é a função que o indivíduo exerce no dia-a-dia a dia para poder obter recursos para sobreviver Entretanto, existem trabalhos não-remunerados (voluntariado), mas eles agregam outros valores que faz o ser humano exercer (sexo masculino, 19 anos, não trabalha).

"Trabalho é desempenhar tarefas quase sempre especificadas mediante remuneração" (sexo masculino, 18 anos, não trabalha).

Essas transcrições remetem à noção do trabalho como meio de obtenção de recursos, noção esta que surge no final da Idade Média e se firma na Moderna com a ampliação do pensamento econômico baseado no mercado, em oposição à concepção clássica (trabalho como tortura). O valor atribuído ao trabalho é alterado, tornando-se fundamental para a economia, ao mesmo tempo em que se converte em símbolo de liberdade e autonomia do indivíduo que, com os recursos alcançados, pode obter os benefícios materiais que deseja. 
Essa visão do trabalho como fonte de obtenção de sustento se reforça ao longo da era industrial que, pautada pelas ideias do liberalismo, de um sistema de concorrência mais intenso, faz com que por muito tempo o trabalho seja entendido como necessariamente atividade em que haja troca da força humana por moeda. A ideia de recompensa também faz com que se considere que os indivíduos que não trabalham sejam vistos como inúteis para a sociedade. $\mathrm{E}$, mais recentemente, o desemprego torna-se um grande risco, capaz de lançar um indivíduo socialmente marginalizado, na medida em que está excluído dos laços de pertença criados pelo trabalho.

Nesse sentido, vale destacar que esses alunos, embora ainda nos primeiros semestres, optaram por um curso em estreita relação com as mudanças do mercado; um espaço em que há muita concorrência e que gera a ideia de um contínuo e intenso desenvolvimento profissional, sobretudo em grandes empresas. Além disso, pelo grupo ser representado por alunos do curso noturno, a busca por uma ocupação como forma de maior independência dos pais e, em alguns casos, a necessidade de sustento, reforça essa representação.

Porém, mesmo que o objetivo para o desenvolvimento profissional seja uma carreira em uma grande corporação, esses estudantes acompanham o expressivo crescimento do terceiro setor nos últimos anos, em que se destaca o trabalho das ONGs, somando-se a isso a importância que tem sido dada para as atividades voluntárias. A ampla divulgação que essas iniciativas possuem na mídia, bem como o incentivo dado pelas instituições de ensino aqui se destaca o Trote Solidário desenvolvido há três anos pela Escola de Administração, quando no ingresso do curso os alunos são chamados a participar de atividades e assistem palestras sobre voluntariado - têm contribuído para modificar a visão de trabalho como emprego ${ }^{5}$. Nessa mesma linha, muitas escolas de ensino médio têm convocado os alunos a integrarem tais empreendimentos solidários como forma de participar da vida social e dar a sua contribuição.

No que se refere às representações ligadas aos objetivos do trabalho, os respondentes destacaram que o trabalho é a "forma de gerar algo útil". Como dizem os alunos "Trabalho é a realização de uma certa atividade com um objetivo que representa, mesmo que inconscientemente", (sexo feminino, 19 anos, não trabalha); e ainda "É toda forma de prestação de serviços, criação, apoio, que esteja pré-determinado ou implícito um objetivo (sexo masculino, 19 anos, trabalha há dois meses).

${ }^{5}$ Neste estudo, fica entendido como emprego toda ocupação que tem, necessariamente, retorno financeiro. 
O trabalho como esforço físico ou intelectual direcionado para algum fim surge com o declínio das civilizações clássicas e o crescimento do poder da Igreja Católica. O trabalho é, ao mesmo tempo, esforço e seu resultado (ALBORNOZ, 1994), capaz de diferenciar o homem de outros animais, indicando o livre arbítrio dos indivíduos e sua capacidade de ação. Essa representação se reforça com o fim do feudalismo e o surgimento da era industrial, quando, além do objetivo divino, de purificação e de sustento, é atribuída ao trabalho a possibilidade de transformar a sociedade, bem como a de crescimento pessoal e mobilidade social.

Mesmo com o enfraquecimento da doutrina católica nos últimos tempos, deve ser considerada a influência que ainda persiste, sobretudo nas sociedades latinas, como o Brasil, considerado o maior país católico do mundo. Soma-se a isso o fato de que muitos alunos cursaram o Ensino Médio em escolas particulares, muitas com uma forte tradição cristã, oferecendo uma representativa formação religiosa em seu currículo.

Considerando a realidade do Curso de Administração, desde as primeiras disciplinas se destaca a importância de buscar resultados, atingir objetivos, melhorar desempenho etc. É um curso em que a maior parte das "escolas de pensamento" apresentadas destaca a importância de vincular as atividades desenvolvidas ao desempenho organizacional com a máxima eficiência. Nesse sentido, o trabalho é um meio de alcançar objetivos e desenvolver a organização, visão esta reforçada pela imagem do curso na sociedade em que tem prevalecido a ideia de gestão com destaque para organização pessoal, administração do tempo, etc.

Quanto às representações sobre a esfera social, destaca-se a possibilidade/necessidade de cada pessoa contribuir para o todo, interagir com sociedades, sentir-se útil. Os informantes afirmam a importância de sentirem-se integrantes do corpo social ressaltando que essa é uma forma de interação que lhes permite alcançar um novo patamar de desenvolvimento, pois possibilita assumir novas responsabilidades e ter novos compromissos. Segue-se a opinião dos universitários:

"A palavra trabalho impõe uma certa obrigatoriedade, uma função específica dentro de um grupo social. Lavar a louça portanto, é algo que podemos ou não fazer, e quando quisermos (a não ser que se trate de atendente de lanchonete)" (sexo masculino, 18 anos, não trabalha). 
"Trabalho é o desenvolvimento de alguma atividade que proporcionará o melhor andamento da sociedade" (sexo masculino, 23 anos, trabalha há três anos).

"Trabalho é uma atividade realizada por um individuo que tem como objetivo a geração de um produto ou de um serviço a sociedade, ou alguns de seus membros. Ele tem como conseqüência em muitos casos a remuneração" (sexo masculino, 18 anos, não trabalha).

Na sociedade moderna, foi atribuído ao trabalho o papel principal de possibilitar a construção do futuro, a fim de substituir o caos pela ordem, na medida em que passou a ser um importante mecanismo de controle e organização social. Além disso, antes o trabalho era compreendido como atividade em que a humanidade como um todo estava envolvida por seu destino $e$ natureza, e não por escolha, ao fazer parte da história, sendo definido como "um esforço coletivo de que cada membro da espécie humana tinha que participar" (ENRIQUEZ, 1999, p. 171). A atividade laboral como meio de produção de resultado é reforçada mesmo pela crítica ao capitalismo que se desenvolve a partir de Karl Marx (1989; 1998). Nas obras do autor, o trabalho seria central na vida das pessoas, uma vez que representa a própria autoconstrução do ser humano; é expressivo, criativo e desafiante. Porém, ao ser incorporado pelo capital, o trabalho torna-se simples mercadoria, sendo alienante e explorador.

A compreensão do trabalho como elemento integrador da sociedade está presente tanto nos estudos realizados em uma visão positivista (DURKHEIM, 1999) quanto em uma postura mais crítica (MARX, 1989; 1998), o que vem a confirmar os valores típicos de uma sociedade assentada sobre os pilares do trabalho. Seja como forma de emancipação, de construção coletiva, de integração, seja como elemento que estabelece a relação desigual das classes no capitalismo, o pensamento moderno acerca do trabalho afirma sua importância como elemento fundamental para a vida social.

Esse pensamento é reforçado continuamente por expressões universalizadas no discurso popular, os quais foram destacados na segunda etapa da pesquisa. "Deus ajuda quem cedo madruga", "Não deixe para amanhã o que podes fazer hoje", "O trabalho enobrece o homem" são expressões correntes que reforçam a importância do trabalho árduo para a construção da sociedade e valorização do ser humano como alguém nobre e responsável. A quem não trabalha está reservado o papel de desviante: é o 
preguiçoso, o vagabundo, o inútil, alguém que não vive de acordo com os princípios da sociedade.

Na esfera das representações subjetivas/pessoais está a importância do trabalho como fonte de realização pessoal e profissional, como uma forma de alcançar prazer nas atividades executadas. Esse prazer decorre do fato de sentir-se útil, seja pelo sentimento de pertença ao todo da sociedade, seja por poder reconhecer de que forma seu potencial criativo individual está expresso na transformação de qualquer matéria em algo útil, um produto que represente sua capacidade particular de pensar e de desenvolver o que foi idealizado, acompanhando o surgimento de algo novo que o representa enquanto indivíduo.

"O trabalho é a união do útil ao agradável. Nele retiremos o sustento, mas também buscamos a realização pessoal e obrigação profissional" (sexo masculino, 22 anos, trabalha há quatro anos).

Essa representação engloba desde o conceito clássico de trabalho como atividade de emancipação humana, presente na obra de Marx, até estudos contemporâneos na linha da psicopatologia do trabalho. Nessa linha, Dejours (1987; 2000) aborda a dicotomia prazer e sofrimento, considerando que o trabalho que permite identificação do indivíduo tanto com o processo pelo qual o produz quanto com o objeto final, resulta em fonte de prazer e satisfação para o mesmo.

Também se encontram relacionados os estudos da escola sociotécnica e aqueles sobre qualidade de vida que ressaltam a importância da autonomia, do feedback, das relações pessoais, da identificação do indivíduo com a atividade realizada para satisfação. Entre os teóricos mais estudados na Administração, Maslow em seus estudos destaca a autorrealização como a necessidade mais ampla e difícil de ser alcançada pelos trabalhadores, mas sempre um fator fundamental para motivação.

Ainda que pouco referenciadas, expressões que apontam um caráter negativo do trabalho, visto como fonte de exploração, de sofrimento e pouco prazeroso, também foram apresentadas, como pode ser visto em expressões como: "Trabalho é qualquer atividade obrigatória necessária a sobrevivência. Cada vez se torna menos prazeroso" (sexo feminino, 19 anos, não trabalha) ou "Pagar 200 por 8 horas de trabalho no caso de estagiários, isto não é trabalho é exploração!" (sexo feminino, 19 anos, trabalha há três meses). 
O trabalho como elemento ligado apenas à satisfação das necessidades básicas é a representação das sociedades antigas (grega e romana), em que predominava a escravidão e o espaço de participação, o debate e a constituição da sociedade estavam relegados a um pequeno número de pessoas.

O ressurgimento da concepção clássica pode estar relacionado com o aumento da dificuldade da inserção profissional, mesmo para jovens com nível superior. Em função da flexibilização das formas de contrato de trabalho, aqui se destacam os estágios não obrigatórios, apontados como a principal forma de ingresso de jovens no mercado. O estágio é o meio pelo qual o estudante entra no mercado de trabalho com relativa facilidade, sem a necessidade de estar empregado e sem carteira assinada, já que precisa apenas de um curso adequado às demandas da organização e de demonstrar habilidades $e$ atitudes de acordo com as vagas oferecidas para ser admitido (VILELLA; NASCIMENTO, 2003). Em sua proposta inicial, os estágios não obrigatórios foram criados para serem atividades de complementação dos estudos e têm como objetivo conciliar os conhecimentos teóricos, ministrados em sala de aula, com a realidade do mundo do trabalho. Porém, os interesses que têm levado as empresas a buscarem estagiários são decorrentes da necessidade de mão de obra de baixo custo ou uma ferramenta de captação de recursos humanos de acordo com a necessidade de realimentação do quadro funcional (VILLELA; NASCIMENTO, 2003). Para as vagas oferecidas, entretanto, muitas vezes, os estudantes não utilizarão as habilidades requisitadas, tampouco conhecimentos específicos como idiomas ou cursos técnicos, ficando restritos à execução de tarefas operacionais, que pouco contribuem para sua formação profissional (MELO; QUIROGA, 2003)

Embora o estudo realizado seja em uma instituição pública e tenha se privilegiado estudantes com menos de 24 anos, é possível fazer uma aproximação com os resultados encontrados por Cavedon (1999) ao estudar as representações sociais de estudantes do curso de Administração de Recursos Humanos de uma universidade privada do Rio Grande do Sul. No conjunto, as representações aqui encontradas são bastante similares às daquele estudo, contudo notam-se algumas diferenças: as representações materiais estão mais presentes neste estudo do que no de 1999, mesmo se considerarmos apenas a questão de retorno financeiro, já que a relação do trabalho com alcance de resultados não foi referida no estudo de Cavedon. Essa inversão pode estar relacionada com o contínuo incentivo que os estudantes têm recebido para ingressarem logo no mercado de trabalho, para adquirir maior 
independência e liberdade, valores que são reforçados pela sociedade de consumo e pelos cursos de Administração.

Outro ponto marcante é a preocupação com a exploração do trabalho por meio dos estágios. No trabalho de Cavedon (1999), alguns alunos já apontavam a preocupação com a busca pelo emprego; contudo, no estudo atual já surgem inquietações com a qualidade da ocupação e as limitações de retorno financeiro que terão esses jovens, mesmo constituindo um grupo considerado privilegiado da população brasileira.

De maneira geral, as representações encontradas apontam para uma imagem abrangente e ampliada de trabalho, que contempla o indivíduo tanto na sua dimensão coletiva quanto na subjetiva, tanto na esfera da atividade remunerada quanto na da não remunerada, tanto material quanto imaterial, elementos que permitem reforçar a centralidade da categoria trabalho na formação societal contemporânea. O trabalho permite não apenas a riqueza e a acumulação de bens, mas também o desenvolvimento de forças produtivas. Ao mesmo tempo, constitui o cimento social, o fator básico da socialização, a atividade principal e o elemento definidor de boa parte do sentido da vida dos indivíduos. Dessa forma, constitui um elemento essencial de construção identitária e de socialização, e a principal ou a única maneira de se obter recursos materiais e imateriais necessários no presente modelo de vida em sociedade, podendo ser fonte de satisfação, por permitir participar da obra produtiva geral e fonte de verdadeiro prazer, por possibilitar a realização de objetos úteis à sociedade.

\section{Lazer X Trabalho}

Com a questão "o que não é trabalho?", buscou-se reforçar as representações dos informantes sobre o tema a partir de elementos que entendem como sua negação. Repetiram-se os grupos de representações utilizados na afirmação, pois grande parte dos informantes buscava a negação do que havia referido na questão anterior. Assim, a partir das categorias material, social e subjetivo/pessoal, foi incluído um elemento que permitiria a contraposição ao labor em qualquer das esferas.

Com maior destaque como contraposição ao trabalho está o lazer. Tal como na fábula da formiga e da cigarra - que não por acaso foi a história mais referenciada quando perguntados em que lembranças poderiam pautar 
suas respostas -, para os informantes, atividades que não "geram algo de produtivo" não configurariam trabalho. Nessa linha estariam atividades de entretenimento (cinema, teatro, etc.); estar com os amigos ou com a família; $e$ mesmo o ócio propriamente dito. Essas seriam atividades que não têm um objetivo, que não contribuem para uma organização ou para a sociedade, bem como não proporcionariam relações sociais objetivas, de responsabilidade, etc.

"Lazer. Lazer não é trabalho, aliás, lazer é uma forma de se refugiar do trabalho. É uma forma de relaxar, de fugir da realidade. De não ter responsabilidades. Mas também essencial para o ser humano" (sexo feminino - 19 anos não trabalha).

Na hora que a pessoa está em um momento de lazer (salvo quando ela considera um lazer o seu trabalho) ela não está exercendo nenhum tipo de trabalho. Como exemplo de um "não-trabalho" é a convivência da pessoa com sua família (sexo feminino, 19 anos, não trabalha).

A percepção de atividades como lazer, divertimento, repouso, ócio estão em contraposição ao trabalho desde as civilizações clássicas; o que muda é a posição que ocupam na vida dos seres humanos. Como nas sociedades grega e romana o lazer e o ócio eram valorizados, em detrimento do trabalho, na sociedade moderna ocorre uma inversão. A partir da Idade Média, por influência da Igreja, o lazer passa a ser entendido como a recompensa pelo trabalho: "No sétimo dia Deus descansou". Esse valor que é reforçado no início da era industrial, permanece até hoje.

Nas representações materiais, foram expressas atividades que não têm como retorno dinheiro ou que sejam executadas sem o sentido de atingir um resultado. Como expressa a aluna "o não-trabalho são ações realizadas sem finalidade, sem objetivo. Em qualquer campo seja escola, emprego, o que nos faz ter um crescimento como pessoa frente ao trabalho" (sexo feminino, 19 anos, não trabalha).

Nessa ideia ainda está muito forte o pensamento do trabalho assalariado, do emprego, que para muitos constitui uma forma de ocupação em que o indivíduo, sem esforço e sem buscar atingir um objetivo maior, receberia algo em troca. Essa linha é reforçada pela crença na forma de atuar das repartições públicas no Brasil, a qual se acredita que os servidores não trabalham, 
mas apenas cumprem horário, desconsiderando as necessidades daqueles que requisitam o serviço. Também nessa linha inclui-se a visão popular de trabalho "burocrático" em que o individuo executaria atividades repetitivas sem identificar para que serviriam.

Embora, alguns, posteriormente, busquem a estabilidade do setor público, no imaginário dos estudantes apresentam-se como opostos: o dinamismo das organizações privadas ao atraso e lentidão das públicas. Tanto é que o curso da UFRGS que é de "Administração" visto que procura contemplar como a gestão se apresenta em diferentes tipos de organizações, comumente é nomeado pelos alunos de Administração de Empresas, não considerando as organizações públicas e mesmo as do Terceiro Setor.

Na esfera social, ressalta-se que não seria trabalho o que não serve para a sociedade. Quem não desenvolve uma atividade que tenha um fim social como objetivo não estará contribuindo para o todo, estará agindo de forma egoísta, etc., como afirmam os depoimentos.

"Acho que quando se faz algo para benefício próprio, sem com esta ação ajudar algum individuo, isso não é trabalho" (sexo masculino, 18 anos, não trabalha).

"Não é trabalho tudo aquilo que não gere nem produza nada em prol de um bem comum da humanidade" (sexo masculino, 19 anos, não trabalha).

Mesmo em um curso em que predomina a concorrência e uma realidade baseada no individualismo, afirma-se a necessidade do trabalho como meio de contribuir para a sociedade. Talvez isso seja um dos motivos pelos quais cresce o número de pessoas que realizam trabalho voluntário, uma vez que dentro das empresas com fins exclusivamente lucrativos, as pessoas trabalhariam apenas para o beneficio próprio.

De maneira geral, a imagem do não trabalho é a da cigarra, que canta enquanto a formiga trabalha; uma personagem individualista, que vive só, sem preocupação com o coletivo; alguém que realiza uma atividade que não produz algo, sem valor, que não tem um objetivo. Enfim, a imagem daquele que vive no egoísmo e não se esforça para o bem do grupo. A imagem do desviante, inútil, vagabundo que se firmou na sociedade ocidental moderna, uma sociedade que prima por valores assentados no trabalho. 


\section{Reflexões Finais}

Apesar das mudanças ocorridas no mundo do trabalho, em que se destaca o aumento do desemprego, das tecnologias industriais e do contingente de mão de obra operando em condições que não se enquadraria no típico posto formal, o trabalho continua sendo categoria fundamental na vida dos indivíduos. Seguem destacando que, além da dimensão econômica indispensável para a satisfação de necessidades materiais, contribui para a manutenção da ordem moral, econômica, social, jurídica, política e cultural presente, ao funcionar como uma forma de regulação social; torna-se um elemento fundamental na constituição da condição humana, ao ser um fator determinante da experiência humana na integração ao meio e realização pessoal, bem como um legitimador das diferentes fases da vida (estudo, trabalho, aposentadoria).

Mesmo que sete anos separem este trabalho do de Cavedon (1999) e ambos terem sido realizados em ambientes distintos, neste permanecem, em grande parte, as representações encontradas naquele estudo. Porém, é possível notar algumas diferenças marcantes: a crescente importância da visão de que trabalho não precisa ser remunerado, principalmente como resultado do crescimento do Terceiro Setor; a vinculação do trabalho a resultados e a sua realização em uma organização, que reforça a importância que as empresas têm recebido, sobretudo, nas sociedades ocidentais; e, ainda, a preocupação de que o labor se torne uma forma de exploração, vinculado à crescente flexibilização das formas de trabalho, para os universitários, de forma muito marcante nos estágios.

Deve ser destacado que os componentes do estudo encontram-se predominantemente em um grupo social que não reflete a totalidade da sociedade brasileira, com acesso a escolas particulares, dispondo de uma alta renda e morando em uma capital. Mesmo assim, existem representações do trabalho como meio necessário para o sustento e independência. Acredita-se que embora estejam vinculando esses resultados à necessidade de sobrevivência, os informantes podem estar vendo o trabalho como uma forma de satisfazer desejos materiais, ainda que não fundamentais, uma forma de ter "liberdade como consumidores".

Também é notável o destaque dado à importância social do trabalho, quando se encontram em um curso que está muito mais voltado para a construção de uma carreira individual e um meio em que existe muita concorrên- 
cia. Para analisar essas questões, pretende-se continuar o estudo focando um grupo menor de indivíduos e trabalhando com entrevistas em profundidade em que se poderá buscar o processo de formação dessas representações no conjunto das referências dos informantes, tal como sugere Spink (1997).

Embora as representações apresentadas reflitam, de maneira geral, o caráter positivo do trabalho, o surgimento da preocupação que este trabalho se torne uma forma de exploração, sobretudo para os novos entrantes no mercado, merece atenção. Considerando a importância que o trabalho tem para todos os indivíduos - fato verificado neste estudo e destacado por diversos autores - a construção de uma representação predominantemente negativa pode trazer sérios problemas tanto para a "ordem social" quanto para as expectativas individuais.

Assim, acredita-se que devam ser ampliados estudos sobre esse grupo social - a juventude - de modo que abranjam outros grupos das "diferentes juventudes" que compõem o contexto social brasileiro. Levando-se em conta que ainda estão formando a base de suas crenças, conhecer as representações desses indivíduos, suas preocupações e suas vivências permitem antecipar possíveis reflexos das mudanças em curso.

\section{Work as Representation: the view of young university students}

\section{Abstract}

One period of particular importance in the relation of the individual to the world of work is the transition from youth to adulthood, when, among other modifications (biological, psychological and social), entry into the job market has a fundamental role, marking a new stage of life. Hence, this study seeks to analyse which social representations are present in the speech of young students of a Management course with regard their understanding of the "work". For this purpose, 120 young university students attending the first semesters of an evening Management course at a university in the south of Brazil were consulted. The responses regarding "what is work" and "what is not work" were written by the informants themselves and later analysed in relation to the frequency with which they occur and their diversity. In general, it is noted that work continues to be understood as the central activity that structures the life of individuals and of society in general, a form of social integration, in which its image prevails as an element that inserts the individual in 
the environment, capable of leading to personal and professional fulfilment as well as to financial sustenance.

Key words: Work Social Representations. Young University Students. Management.

\section{Referências}

ALBORNOZ, Suzana. O que é trabalho. São Paulo: Brasiliense, 1994.

ANTUNES, Ricardo. Os sentidos do trabalho: ensaio sobre a afirmação e a negação do trabalho. São Paulo: Boitempo, 1999.

BORGES, Lívia. As concepções do trabalho: um estudo de análise de conteúdo de dois periódicos de circulação nacional, RAC - Revista de

Administração Contemporânea, v. 3, n. 3, set./dez. 1999.

CAVEDON, Neusa Rolita. As Representações Sociais dos Universitários sobre o Trabalho. In: XXVIII ENANPAD. Anais...Foz do Iguaçu. 1999.

CAVEDON, Neusa Rolita. Representações sociais na área de gestão em saúde: teoria e prática. Porto Alegre: Dacasa, 2005.

CATTANI, Antônio David. Trabalho e autonomia. Petrópolis: Vozes, 2000.

CHAHAD, José Paulo Z.; PICCHETTI, Paulo. A Evolução da Taxa de Desemprego Estrutural no Brasil: uma análise entre regióes e características dos trabalhadores In: CHAHAD, José Paulo Zeetano; PICCHETTI, Paulo (Org.);

Mercado de Trabalho no Brasil: padrões de comportamento e transformações institucionais, Cap. 12, p. 361-400, São Paulo: LTr, 2003.

DEJOURS, Christophe. A loucura do trabalho: estudo de psicopatologia do trabalho. São Paulo: Cortez, 1987.

DEJOURS, Christophe. A banalização da injustiça social. Rio de Janeiro: Fundação Getúlio Vargas, 2000.

DE MASI, Domenico. O ócio criativo. 5. ed. Rio de Janeiro: Sextante, 2000. 
DE MASI, Domenico. O futuro do trabalho: fadiga e ócio na sociedade posindustrial. Rio de Janeiro: J. Olympio, 1999.

DURKHEIM, Émile. Da Divisão do Trabalho Social. São Paulo: Martins Fontes, 1999.

DURKHEIM, Émile. As formas elementares da vida religiosa: o sistema totêmico na Austrália. São Paulo: Martins Fontes, 1996

ENRIQUEZ, Eugène. Perda do trabalho, perda da Identidade. In: NABUCO, Maria Regina; CARVALHO NETO, Antônio. (Orgs). Relações de trabalho contemporâneas.Belo Horizonte: IRT da PUC de MG, 1999, p. 69-83.

FARR, Robert M. Representações Sociais: A teoria e sua história. In: GUARESCHI, Pedrinho; JOVCHELOVITCH, Sandra. Textos em Representações Sociais. Petrópolis: Vozes, 1997.

FERREIRA, José Maria Carvalho. Trabalho e sindicalismo no contexto da globalização, 2002.

JODELET, Denise. Lês Respresentations Sociales. Science Humaines. n. 27, avril, 1993.

JOVCHELOVITCH, Sandra. Vivendo a Vida com os Outros: intersubjetividade, espaço público e representações sociais. In: GUARESCHI, Pedrinho e JOVCHELOVITCH, Sandra. Textos em Representações Sociais. Petrópolis: Vozes, 1997.

KOVÁCS, Ilona. As metamorfoses do emprego: ilusões e problemas da sociedade da informação. Oeiras, Portugal: Celta, 2002.

MARX, Karl. O Capital: crítica da economia política. Rio de Janeiro: Civilização Brasileira, 1998.

MARX, Karl. Manuscritos econômicos e filosóficos. Rio de Janeiro: Zahar, 1989.

MÉDA, Dominique. Le Travail, une valeur en voie de disparition. Paris: Flammarion-France, 1999. 
MELO, Frederico Luiz Barbosa; QUIROGA, Júnia Valéria. Super-exigidos, segmentados e estigmatizados: jovens "educados" num mercado de trabalho com alto desemprego. VIII Encontro Nacional de Estudos do Trabalho - ABET, Anais...São Paulo, 2003.

MORIN, Estele; TONELLI, Maria José; PLIOPAS, Ana Luísa Vieira. O trabalho e seus sentidos. In: ENANPAD, 27, 2003, Atibaia. Anais... Atibaia, ANPAD, 2003. 1CD-ROM

MORIN, Estelle. Os Sentidos do Trabalho. RAE - Revista de Administração de Empresas. v. 41, n. 3, p. 8-19, jul./set., 2001

MOSCOVICI, Serge. Prefácio. In: GUARESCHI, Pedrinho; JOVCHELOVITCH, Sandra.Textos em Representações Sociais. Petrópolis: Vozes, 1997.

NEFFA, Julio C. El trabajo humano: Contribuições al estudio de un valor que permanece. México: Hvmanitas, 2003.

OFFE, Claus. Trabalho: A categoria-chave da sociologia? Revista Brasileira de Ciências Sociais, v. 4, n. 10, jun, 1989.

PICCININI, Valmiria et alii, Buscando o sentido do trabalho. Relatório de Pesquisa. Porto Alegre: UFRGS/CNPq. 2004.

RIFKIN, Jeremy. O fim dos empregos: o declínio inevitável dos níveis dos empregos e a redução da força global de trabalho. São Paulo: Makron, 1995.

SALAMON, Lester. A emergência do terceiro setor - uma revolução associativa global. RAE - Revista de Administração de Empresas. v. 41, n. 3, p. 819, jul./set., 2001.

SPINK, Mary Jane. Desvendando as Teorias Implícitas: uma metodologia de análise das Representações Sociais. In: GUARESCHI, Pedrinho; JOVCHELOVITCH, Sandra. Textos em Representações Sociais. Petrópolis: Vozes, 1997.

SPINK, Mary Jane Práticas discursivas e produção de sentidos no cotidiano: aproximações teóricas e metodológicas. São Paulo: Cortez, 2004.

VILLELA, Lamounier Erthal Villela; NASCIMENTO, Leyla Maria Felix do, Competências Pós-Industriais Exigidas pelas Empresas a Estagiários e RecémFormados. In.: Anais do XVII Enanpad: Atibaia, Setembro de 2003 ENANPAD 2002. RJ: Metrópole, 2003. v. 1. 